\title{
Development of a Novel Process to produce Biodiesel and its use as fuel in CI Engine performance study and exhaust analysis
}

\author{
Prasheet Mishra ${ }^{1}$, D.V.N. Lakshmi ${ }^{2}$, D.K.Sahu ${ }^{3}$ \\ ${ }^{I}$ Assistant Professor, Department of Marine Engineering, C.V.Raman College of Engineering, Biju Patnaik \\ University of Technology, Bhubaneswar, India, \\ ${ }^{2}$ Assistant Professor, Department of Mechanical Engineering, C.V.Raman College of Engineering, Biju Patnaik \\ University of Technology, Bhubaneswar, India, \\ ${ }^{3}$ Professor, Department of Chemistry, C.V.Raman College of Engineering, Biju Patnaik University of \\ Technology, Bhubaneswar, India,
}

\begin{abstract}
A novel process has successfully been developed by overcoming major difficulties through the elimination of number of process steps involved in the Classical Transesterification reaction during the preparation of Fatty Acid Methyl/Ethyl Ester (FAME.FAEE) called biodiesel. The Classical process with cost intensive process steps such as the utilization of excess alcohol, needing downstream distillation for the recovery and reutilization of excess alcohol/cosolvent, unrecoverable homogenous catalyst which consumes vast quantity of fresh distilled water during the purification of the product and downstream waste water treatment before its safe disposal to the surface water body. The Novel Process FAME/FAEE is produced from any vegetable oil irrespective of edible or inedible variety using sonication energy. The novelty of the finding is the use of only theoretical quantity of alcohol along with a co-solvent and reduced quantity of homogeneous catalyst. Under this condition neither the homogeneous catalyst goes to the FAME layer nor is the distillation needed. The same ester also has been prepared in high pressure high temperature reactor without using catalyst at sub critical temperature. The quality of prepared biodiesel without involving any purification step meets the ASTM standards. Blended Biodiesel with Common Diesel Fuel (CDF) and FAME is prepared, characterized and used as fuel in the Kirloskar make CI Engines. The evaluation of the engine performance result of pure $C D F, B 05$ biodiesel, B10 biodiesel of all types of biodiesel prepared by using the feedstock of Soybean (Glycine max) and Karanja (Pongamia pinnate) oil along with their mixed oil provides useful information such as brake power, brake thermal efficiency, brake specific fuel consumption, etc, and established it as ideal fuel for unmodified CI engine.
\end{abstract}

Keyword: Novel Process, Transesterification, Sonication, High Pressure Reactor

\section{Introduction}

Tremendous search is going on to meet the demand of increasing requirement of environmental friendly biodiesel to substitute conventional common diesel fuel (CDF) used in IC engines in the transport sector. Biodiesel is produced from plant oils, animal fats, used cooking oil and algae through energy intensive transesterification reaction and termed as classical process [4-6]. It becomes challenge to minimize the cost of its production mainly through the reduction of process parameters/steps by adopting various techniques: Situtransesterification [7], use of ultrasonic energy in the range of $20-100 \mathrm{kHz}$ or more, use of cosolvent to reduce excess amount of alcohol uses in the reversible process for driving it forward direction [4] but followed with recovery of cosolvent, employing catalyst free critical methanol/ $\mathrm{CO}_{2}$ replacing homogeneous with heterogeneous catalyst [8], carry out the reaction in ionic liquid [9], etc. For the first time, the researchers have made both the use of ultrasound energy and cosolvent to speed up the reaction and obtain a high yield of product with much less reaction parameters. Although the application of ultrasound energy helped to reduce the reaction time and temperature, yet the amount of alcohol used was still in excess and due to its polarity, alkali catalyst sleeps into the FAME layer causing the consumption of vast quantity of distilled water for its purification, and the loss of catalyst. Hence a cosolvent has been used in addition to ultrasound energy to reduce the mass transfer limitations arising due to the immiscibility of the alcohol and oil layers thereby reducing the consumption of alcohol and catalyst. Boocock et al [4] suggested that addition of a cosolvent such as THF could enhance the miscibility of the phases and speed up the reaction rate because of the disappearance of the interphase mass transfer resistance in the heterogeneous two-phase reaction system. Several studies have been carried out till date using cosolvents for transesterification and interesting results have been found out. Thanh et al.[5] developed a homogeneous reaction process using acetone as cosolvent for transesterification and found that a FAME yield of more than $98 \%$ was obtained in just 30 minutes with $\mathrm{MeOH} /$ oil molar ratio $4.5: 1$, catalyst $(\mathrm{KOH})$ concentration $1 \mathrm{wt} . \%$, and cosolvent $25 \mathrm{wt} . \%$. Li et al.[6,7] used dichloromethane as cosolvent for the homogeneous alkali catalyzed transesterification of soybean oil and found that the optimum conditions for the 
reaction were $\mathrm{MeOH} /$ oil molar ratio 4.5:1, catalyst $(\mathrm{KOH})$ concentration $1 \mathrm{wt} . \%$, cosolvent $4 \%$, temperature $45^{\circ} \mathrm{C}$ and a total reaction time of 45 minutes. At methanol/oil molar ratio of $6: 1$, temperature $25^{\circ} \mathrm{C}$ and in the presence of cosolvent the sunflower oil was almost completely converted to biodiesel in just 20 minutes of reaction time whereas the same reaction without cosolvent gave only $78 \%$ conversion. Heterogeneously catalyzed transesterification reaction in the presence and absence of cosolvents has also been investigated $[8,9]$. Although co solvents help to accelerate the transeseterification reaction, but they have to be recovered and reactivated from the product biodiesel during its purification for its reuses which not only makes the task difficult, but also increases the cost of biodiesel production. The current paper makes the use of fossil fuel as a cosolvent where it need not be removed from the product as it could be used as a biodiesel-CDF blended [ASTM No- ] fuel in an unmodified compression ignition (CI) engine. The greatest advantage of using large amount of nonpolar character cosolvent is to avoid the solubility of alkali catalyst in the FAME layer, thus completing the process in single step for the first time. Biodiesel produced through various technique are taken for the study of $\mathrm{CI}$ engine performance by prominent researchers to establish its acceptability as ideal fuel and publishing their own interpretation. Prominent publications are reported from A.KAgrawal, Pratik Behera, S.S.Singha, D.C.Pakopouls and others. Achieving the success in reducing the multi energy intensive transesterification reaction to single step to produce biodiesel from vegetable oil, attempts are taken to report on the study of CI engine performance using the product biodiesel blended fuel [8]. The reasons of variation from the basic date of $\mathrm{CDF}$ are explained taking unmodified CI engine structure with the chemical nature of biodiesel.

\section{Preparation Of Bio Diesel}

Two types of vegetable oil was taken to prepare biodiesel and used to study the performance:

\subsection{Type-1: (Soybean Oil)}

Edible variety Refined Soybean oil was procured from the local retail shop and analyzed. The free fatty acid, moisture and phospholipids contents were found to be the noninterference level of carrying transesterification reaction. Analar quality of sodium hydroxide and methanol were of M/s Finar Ltd. Co, solvent selected here is a typical fossil fuel procured from the local market and analyzed to find to objectionable impurities to cause interference either in the transesterification or in the CI engine.

The transesterification reaction carried out here was of batch type. For each batch, soybean oil taken was of $100 \mathrm{gm}$. The reaction was carried out in a special designed 2 litre capacity Boro glass three necked round bottom reactor placed on a heating metal to provide appropriate temperature. Oil was initially heated to $5^{0} \mathrm{C}$ below the desired temperature. Methanol-sodium hydroxide homogeneous solution was prepared earlier and stored on freshly prepared anhydrous sodium sulphate. Stochiometric quantity of alcoholic sodium hydroxide was drawn into the reaction vessel. The desired temperature was allowed to achieve. Optimum quantity of co solvent was slowly added into the reaction vessel so that the set temperature was not disturbed. The ultrasonic energy is employed to carry out the transesterification reaction. The special designed probe, thermocouple and reflux condenser were placed ideally. The reaction was carried out for $15 \mathrm{mins}$. The products were suitably transferred to the $500 \mathrm{ml}$ separating funnel. Instantaneously, heavy glycerol was separated as lower one while the lighter one was light pale yellow of Fatty Acid Methyl Ester (FAME).

Deep brown coloured Glycerol was separated and kept for its purification or other uses. FAME was analysed to find the free alkali and moisture content. Non of the constituents were found to be absent. So the product was taken without purification for Thin Layer Chromatograph/Gas Chromatograph analysis.

\section{Blended FAME (Biodiesel):}

B-05 and B-10 blended fuel were prepared by mixing $50 \mathrm{ml}$ of FAME with $950 \mathrm{ml}$ of common diesel fuel (CDF). B-10 blend was prepared by mixing $100 \mathrm{ml}$ FAME with900 $\mathrm{ml} \mathrm{CDF}$.

\subsection{Type-2 : (Karanja Oil)}

Non-edible variety Karanja (Pongamia Pinnate) was procured from the native of Bhadrak. On analysis it was found to contain Free Fatty Acid (FFA) $\sim 10 \mathrm{mg} \mathrm{KOH} / 100 \mathrm{gm}$ of oil, $\sim 5 \%$ moisture and $2.5 \%$ phospholipids besides some floating vegetable materials. The FFA content was reduced by treating the crude oil with methanol in presence of sulphuric acid. After reaction the FFA content found to reduce. The crude oil after FFA content reduction treated with alkali wash to remove sulphuric acid. The oil was then put into sonication. Both phospholipids and moisture content were reduced to below the interference level. The transesterification reaction and blending were carried out in the same process as described earlier. . So the product was taken without purification for Thin Layer Chromatograph/Gas Chromatograph analysis.

\section{Blended FAME (Biodiesel):}

B-05 blended fuel was prepared by mixing $50 \mathrm{ml}$ of FAME with $950 \mathrm{ml}$ of CDF. 


\section{Engine Description :}

This methodology is based on experimental tests performed in a single cylinder engine since such type of facility generates much more accurate data compared to multi cylinder engine. Therefore the study has been carried out in a single cylinder, multi fuel VCR (computerized) research engine set up. The set up consists of single cylinder, four stroke, multi fuel, research engine connected to eddy current type dynamometer for loading. The compression ratio can be varied without stopping the engine and without altering the combustion chamber geometry by specially designed tilting cylinder block arrangement. Rota meters are provided for cooling water and calorimeter water flow measurement. A battery, starter, battery charger is provided for engine electric start arrangement. The set up enables to study the engine performance for Brake Mean Effective Pressure, Mechanical Efficiency \& Specific Fuel Consumption.

\subsection{Engine Technical Specifications :}

Table I: Brief Technical Specifications Of The Research Engine

\begin{tabular}{|l|l|l|}
\hline \multicolumn{1}{|c|}{ Serial No. } & \multicolumn{1}{|c|}{ DTEM } & \multicolumn{1}{c|}{ DESCRIPTION } \\
\hline 01. & Make & TVirloskar Oil Engines \\
\hline 02. & Model & Research Diesel Engine \\
\hline 03. & Type & 661.5 \\
\hline 04. & Displacement $\left(\mathrm{Cm}^{3}\right)$ & 3.5 \\
\hline 05. & Max.Engine Power $(\mathrm{KW})$ & 22.3 \\
\hline 06. & Max.EngineTorque $(\mathrm{Nm})$ & $87.5 \times 110$ \\
\hline 07. & Bore x Stroke $(\mathrm{mm})$ & $12: 1-18: 1$ \\
\hline 08. & Compression Ratio & 240 bar \\
\hline 09. & Injection Pressure & 1500 \\
\hline 10. & Max.Speed (rpm) & 87.5 \\
\hline 11. & Cylinder Bore $(\mathrm{mm})$ & 110 \\
\hline 12. & Stroke (min) & 234 \\
\hline 13. & Connecting Rod Length $(\mathrm{mm})$ & 4 Stroke \\
\hline 14. & Stroke Type & 1 \\
\hline 15. & Number of Cylinder & Constant \\
\hline 16. & Speed Type & Water \\
\hline 17. & Cooling Type & Diesel \\
\hline 18. & Fuel & 661.5 \\
\hline 19. & Swept Volume $\left(\mathrm{cm}^{3}\right)$ & \\
\hline
\end{tabular}

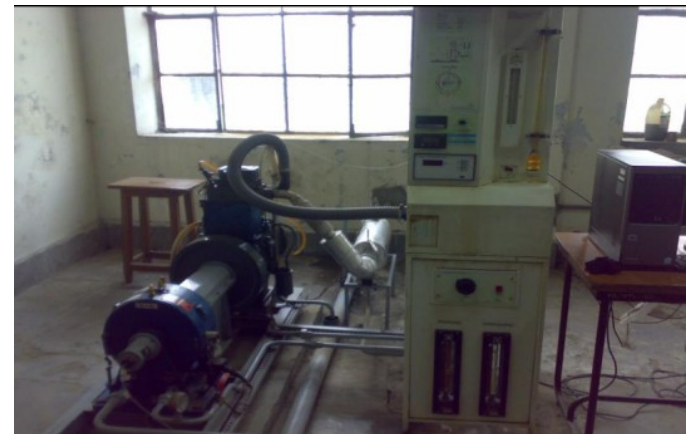

Variable Compression Ratio Engine with Loading Unit \& Data Acquisition unit attached

\subsection{Brake Mean Effective Pressure:}

\section{Results \& Discussions:}

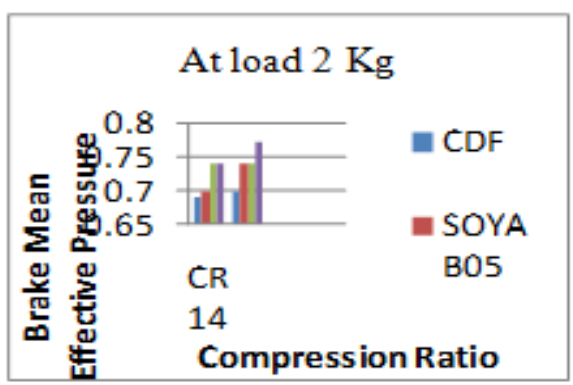

Fig No.3 Brake mean effective pressure for compression ratio $14 \& 18$ at load $2 \mathrm{Kg}$

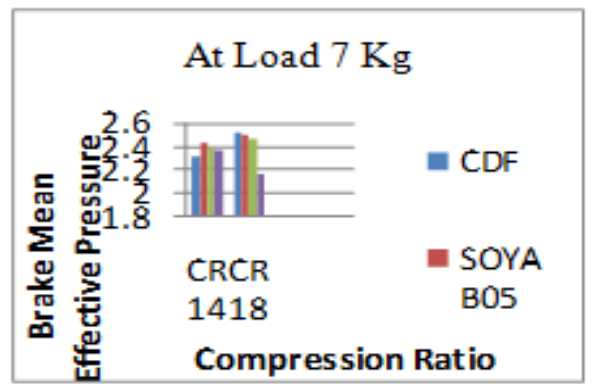

Fig No.4 Brake mean effective pressure for compression ratio $14 \& 18$ at load $7 \mathrm{Kg}$ 
At low load, high and low compression ratio the brake mean effective pressure for CDF is less than that of biodiesel - CDF blend. At higher load, low compression ratio the brake mean effective pressure of CDF is still less than that of biodiesel - CDF blend. But at higher load and higher compression ratio the brake mean effective pressure of CDF is more than that of biodiesel - CDF blend. It was also found that the overall BMEP rises with the increasing FAME in fuel.This may be due to the easy combustion and availability of more unsaturated FAME.

\subsection{Brake Thermal Efficiency:}

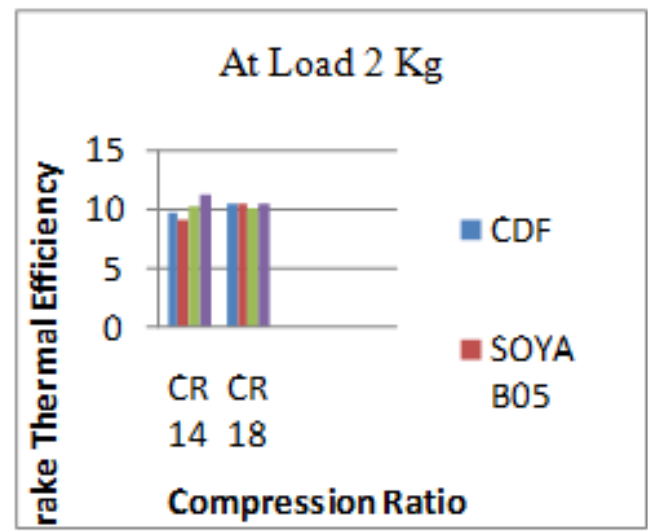

Fig No.5 Brake thermal efficiency for compression ratio14 \& 18 at load $2 \mathrm{~kg}$

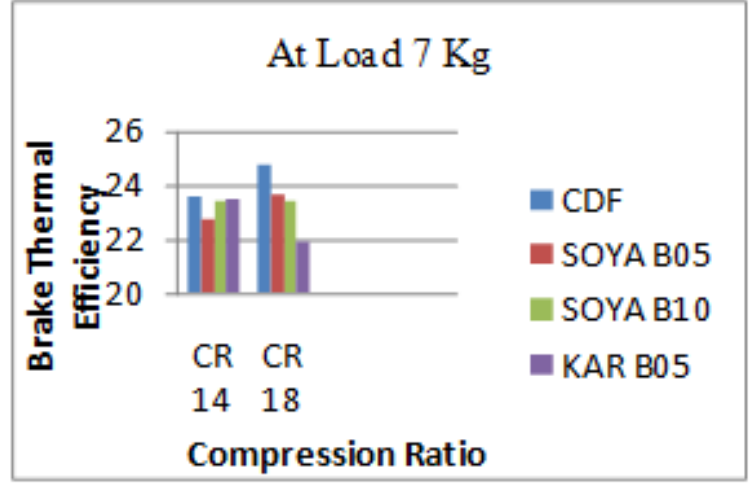

Fig No.6 Brake thermal efficiency for compression $14 \& 18$ at load $7 \mathrm{Kg}$

At low load, low compression ratio the brake thermal efficiency for CDF is more than biodiesel - blend (B05) but less than other biodiesel - CDF blend (B10). At low load, high compression ratio the brake thermal efficiency for $\mathrm{CDF}$ is almost similar to that of a biodiesel CDF blend. At higher load and higher compression ratio the brake thermal efficiency of CDF is marginally higher than the biodiesel - CDF blend.

\subsection{Mechanical Efficiency:}

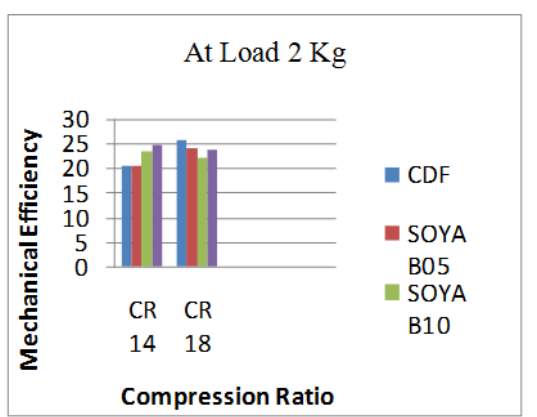

Fig No.7 Mechanical efficiency for compression ratio ratio $14 \& 18$ at load $2 \mathrm{Kg}$

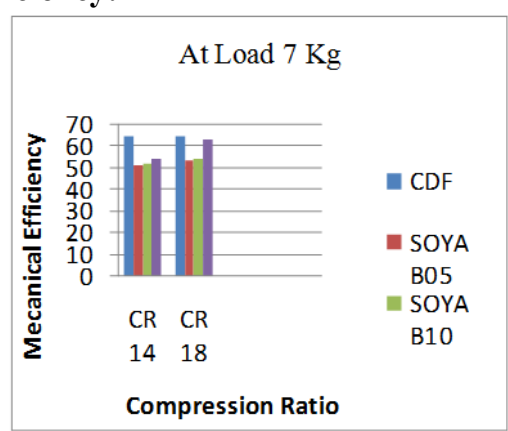

Fig No.8 Mechanical efficiency for compression $14 \& 18$ at load $7 \mathrm{Kg}$

At low load, low compression ratio the mechanical efficiency for CDF is almost similar to biodiesel blend fuel. Except that in any case, in low compression ratio, higher load or high compression ratio higher load the mechanical efficiency for CDF is more than biodiesel - blend fuel. The mechanical efficiency of biodiesel blend fuel is almost similar to CDF at low compression ratio and low load, this might be because of less frictional power for FAME fuel. 


\subsection{Specific Fuel Consumption:}
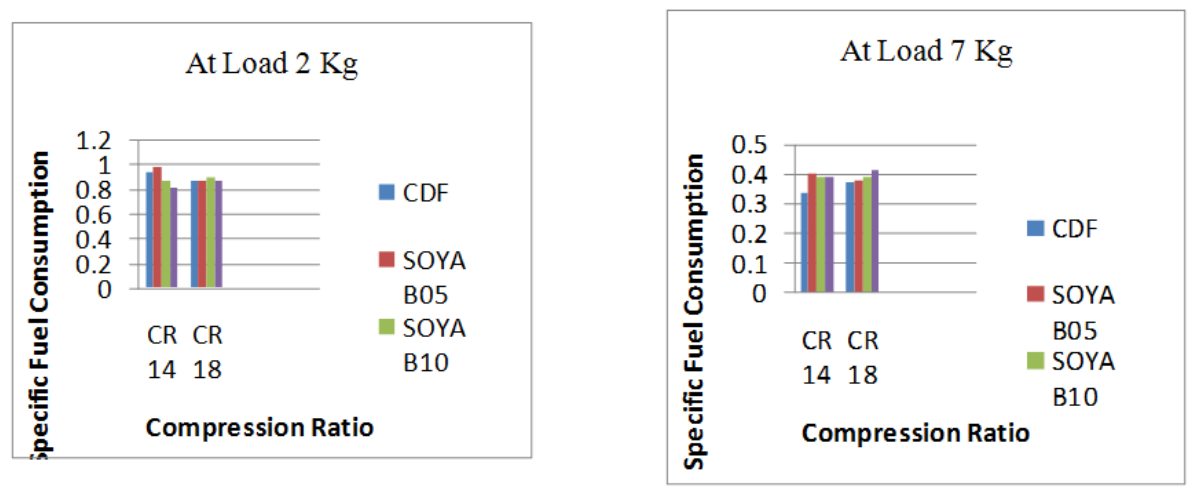

Fig No.9 Specific fuel consumption for compression ratio Fig No.10 Specific fuel consumption for compression ratio $14 \& 18$ at load $2 \mathrm{Kg}$

$14 \& 18$ at load $7 \mathrm{Kg}$

At low load and low compression ratio the Specific Fuel Consumption is almost similar for CDF \& Biodiesel - blend fuel. At high compression ratio and higher load the specific fuel consumption for CDF is less than that of biodiesel - blend fuel. Specific fuel consumption increases with increase in proportion of FAME in the fuel. It is also found that when the load increases the specific fuel consumption for all fuels decreases sharply. Specific Fuel Consumption is calculated on weight basis, so higher the density higher the SFC. So as the density of FAME prepared is less than the CDF, so SFC decreases with increase percentage of FAME.

\section{Exhaust Analysis :}

\begin{tabular}{|c|c|c|c|c|c|c|c|c|c|c|c|c|c|c|c|c|}
\hline \multirow{2}{*}{$\begin{array}{c}\text { Engi } \\
\text { ne } \\
\text { Loa } \\
\text { d }\end{array}$} & \multicolumn{4}{|c|}{ CDF } & \multicolumn{4}{|c|}{ SOYA FAME (B05) } & \multicolumn{4}{|c|}{ SOYA FAME (B10) } & \multicolumn{4}{|c|}{ KAR FAME (B05) } \\
\hline & \multicolumn{3}{|c|}{$\begin{array}{l}\% \mathrm{CO}_{2} \% \mathrm{CO} \\
\mathrm{NO}_{\mathrm{X}}\end{array}$} & $\% \mathrm{O}_{2}$ & \multicolumn{4}{|c|}{$\begin{array}{lll}\% \mathrm{CO}_{2} & \% \mathrm{CO} & \% \mathrm{O}_{2} \\
\mathrm{NO}_{\mathrm{X}} & & \end{array}$} & \multicolumn{4}{|c|}{$\begin{array}{l}\% \mathrm{CO}_{2} \% \mathrm{CO} \% \mathrm{O}_{2} \\
\mathrm{NO}_{\mathrm{X}}\end{array}$} & \multicolumn{4}{|c|}{$\begin{array}{l}\% \mathrm{CO}_{2} \% \mathrm{CO} \% \mathrm{O}_{2} \\
\mathrm{NO}_{\mathrm{X}}\end{array}$} \\
\hline 2 & 1.4 & $\begin{array}{c}0.0 \\
9 \\
\end{array}$ & $\begin{array}{c}18.6 \\
7 \\
\end{array}$ & 26 & 1.8 & $\begin{array}{c}0.0 \\
9\end{array}$ & $\begin{array}{c}18.3 \\
7\end{array}$ & 60 & 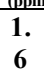 & $\begin{array}{c}0.1 \\
2\end{array}$ & $\begin{array}{l}18.5 \\
2\end{array}$ & 24 & 1. & $\begin{array}{c}0.1 \\
0\end{array}$ & $\begin{array}{c}18.7 \\
4\end{array}$ & 91 \\
\hline 7 & 2.4 & $\begin{array}{c}0.0 \\
5\end{array}$ & $\begin{array}{c}16.9 \\
4\end{array}$ & $\begin{array}{c}16 \\
4\end{array}$ & 2.3 & $\begin{array}{c}0.0 \\
5\end{array}$ & $\begin{array}{c}17.4 \\
7\end{array}$ & $\begin{array}{c}21 \\
0\end{array}$ & $\begin{array}{l}2 . \\
3\end{array}$ & $\begin{array}{c}0.0 \\
6\end{array}$ & $\begin{array}{c}17.3 \\
9\end{array}$ & $\begin{array}{c}15 \\
0\end{array}$ & 2. & $\begin{array}{c}0.0 \\
5\end{array}$ & $\begin{array}{c}17.4 \\
9\end{array}$ & $\begin{array}{c}21 \\
8\end{array}$ \\
\hline
\end{tabular}

Table No. lexhaust Emission Characteristics At Compression Ratio 14

\begin{tabular}{|c|c|c|c|c|c|c|c|c|c|c|c|c|c|c|c|c|}
\hline \multirow{2}{*}{$\begin{array}{c}\text { Engi } \\
\text { ne } \\
\text { Load }\end{array}$} & \multicolumn{4}{|c|}{ CDF } & \multicolumn{4}{|c|}{ SOYA FAME (B05) } & \multicolumn{4}{|c|}{ SOYA FAME (B10) } & \multicolumn{4}{|c|}{ KAR FAME (B05) } \\
\hline & \multicolumn{4}{|c|}{$\begin{array}{llll}\% \mathrm{CO}_{2} & \% \mathrm{CO} & \% \mathrm{O}_{2} \\
\mathrm{NO}_{\mathrm{X}} & & \end{array}$} & \multicolumn{4}{|c|}{$\begin{array}{l}\% \mathrm{CO}_{2} \% \mathrm{CO} \quad \% \mathrm{O}_{2} \\
\mathrm{NO}_{\mathrm{x}}\end{array}$} & \multicolumn{4}{|c|}{$\begin{array}{l}\% \mathrm{CO}_{2} \% \mathrm{CO} \% \mathrm{O}_{2} \\
\mathrm{NO}_{\mathrm{X}}\end{array}$} & \multicolumn{4}{|c|}{$\begin{array}{l}\% \mathrm{CO}_{2} \% \mathrm{CO} \% \mathrm{O}_{2} \\
\mathrm{NO}_{\mathrm{X}}\end{array}$} \\
\hline 2 & 0.7 & 0.01 & 19.78 & 30 & 1.5 & $\begin{array}{c}0.0 \\
3\end{array}$ & 18.74 & 96 & 1. & 0.02 & 18.24 & 82 & 1. & 0.04 & 18.43 & 91 \\
\hline 7 & 2.6 & 0.03 & 16.97 & 207 & 2.3 & $\begin{array}{c}0.0 \\
3\end{array}$ & 17.36 & 255 & $\begin{array}{l}2 . \\
3\end{array}$ & 0.02 & 17.00 & 213 & $\begin{array}{l}2 . \\
3\end{array}$ & 0.02 & 17.12 & 218 \\
\hline
\end{tabular}

Table No.2 Exhaust Emission Characteristics At Compression Ratio 18

It was found that with the percentage decrease in $\mathrm{CO} \& \mathrm{O}_{2}$ there is gradual increase in the percentage of $\mathrm{CO}_{2}$. This is justified as during the chemical reaction of fuel $\mathrm{CO}$ burns with $\mathrm{O}_{2}$ and converted into $\mathrm{CO}_{2}$. That is why there is increase in the percentage of $\mathrm{CO}_{2}$ when the load increases for both compression ratio and for all fuels. There is also increase in percentage of $\mathrm{NO}_{\mathrm{x}}$ with increase in load for all fuels. It shows that the biodiesel blend almost shows similar characteristics as of CDF.Biodiesel reduce the sulphur content also which is present in enormous amount in common diesel fuel which is a major air pollutant. Biodiesel is also called carbon neutral fuel. It is prepared from vegetable oil which comes from plants and when used as fuel in $\mathrm{CI}$ engines and $\mathrm{CO}_{2}$ is obtained in emission is absorbed by the plants only. So biodiesel is not adding up more $\mathrm{CO}_{2}$ in the atmosphere. 


\section{Conclusion}

From the experiments conducted, it was found that the use of ultrasound energy and co solvent simultaneously, could significantly reduce the reaction parameters resulting in a high yield of FAME as well. The performance of the 4-Stroke Variable Compression Ratio Compression Ignition Engine with different load \& compression ratio using this biodiesel blended B05 and B10 was evaluated. The findings on brake mean effective pressure, brake thermal efficiency, Mechanical Efficiency, Specific fuel consumption; parameters at various load and compression ratio are evaluated and explained. Evaluated parameter suggest that the biodiesel obtained from the present study utilizing ultrasonic energy and co solvent may act as an excellent fuel for unmodified CI engine.

\section{References}

[1] Lotero E,Liu Y, Lopez DE, Suwannakarn K, Bruce DA, Goodwin Jr. JG. 2005 ; 44 : 5353-5363. Synthesis of biodiesel via acid catalysis. Industrial and Engineering Chemistry Research.

[2] Zang Y, Dube MA, McLean DD, Kates M; 2003; 89; 1-16. Biodieselproduction from waste cooking oil: 1.Process Design and Technological Assessment; Bioresour Techol.

[3] McCormick RL, Graboski MS, Alleman TZ, Herring AM. 2001; 35, 1742-7. Impact of biodiesel source material and chemical structure on emission of criteria pollutants from a heavy duty engine, Env Sci Technol,

[4] Fukuda H. Kondo A, Noda H. 2001;92;405-16. Biodiesel fuel production by transesterification of oil; J.Biosci. Bioenerg.

[5] Ma F, Hanna MA; 1992; 70; 1-15. Biodiesel production, a review; Biores. Tech

[6] Srivasthava ae, Prasad R, 2000,4, 111-3. Triglycerides based diesel fuel, Renew Sustain Energy Rev,

[7] Amalia Kartika, Yani M, Ariono D, Evon Ph, Rigal L. (2003) 106, 111-17. Fuel

[8] Sahu D.K., Patent Application no-1268/KOL/2011; Published (U/S (5), pp-430-440, Novel transesterification process for the conversion of vegetable oil to low cost biofuel,Indian

[8] Di Serio M, Tesser R, Pengmei L, Santacesaria E, 22:, 201-217, Heterogeneous catalyst for biodiesel production, Energy \& Fuels

[9] Andreani L, Rocha J.O,; A review; (2012) Brazilian J of Chem Eng; 29 (1), Jan-June, 2012. Use of Ionic Liquids in biodiesel production: 